\title{
EVIDENCIA SEROLÓGICA DE ANTICUERPOS CONTRA EL VIRUS DE LA LARINGOTRAQUEITIS INFECCIOSA AVIAR EN GALLINAS REPRODUCTORAS DE CARNE Y POSTURA
}

\author{
Serological Evidence of Antibodies Against Laryngotracheitis Virus in \\ BroILERS AND LAYER B REEDERS
}

Gabriela Yauris S. ${ }^{1,2}$, Eliana Icochea D’A. ${ }^{1,3}$, Rosa González V. ${ }^{1}$ y Néstor Falcón P. 4,5

\section{Resumen}

Un total de 360 muestras de sueros de reproductoras de carne y postura procedentes de 18 lotes de aves, en etapa de producción, fueron examinadas con el fin de detectar la presencia de anticuerpos contra el virus de la laringotraqueitis infecciosa aviar (VLT) mediante una prueba de ELISA indirecta. Las granjas de aves estaban localizadas en la región de Lima y en la costa norte del Perú. Los sueros se colectaron entre julio de 2004 y septiembre de 2005 y fueron analizados en conjunto. Ocho de 360 sueros fueron positivos a anticuerpos contra el VLT. Teniendo en cuenta que las muestras positivas procedían de seis lotes de reproductoras y la baja positividad en estos lotes, se concluye que los 18 lotes de reproductoras analizados no mostraron evidencia serológica de exposición al VLT.

Palabras clave: Virus de Laringotraqueitis Infecciosa Aviar, VLT, anticuerpos, ELISA, gallinas reproductoras

\section{Abstract}

A total of 360 serum samples from eighteen flocks of broiler and layer breeders in phase of production were used in order to detect the presence of Laryngotracheitis virus (VLT) antibodies using a commercial ELISA test. The poultry farms were located in the region of Lima and in the northern coast of Peru. Samples were collected from July 2004 till September 2005 and were processed as a group. Eight samples out of 360 in 6 flocks were positive to antibodies against VLT. Due to the small number of positives and the low level of antibodies was concluded than the 18 breeder flocks did not show serological evidence of exposition to VLT.

Key words: Laryngotraqueitis virus, VLT, antibodies, ELISA test, breeder hens

\footnotetext{
${ }^{1}$ Laboratorio de Patología Aviar, ${ }^{4}$ Laboratorio de Medicina Veterinaria Preventiva, Facultad de Medicina Veterinaria, Universidad Nacional Mayor de San Marcos, Lima

${ }^{2}$ E mail: gabyauris@hotmail.com

${ }^{3}$ Email: micochead@unmsm.edu.pe

${ }^{4}$ Dirección actual: Facultad de Veterinaria y Zootecnia, Universidad Peruana Cayetano Heredia, Lima
} 


\section{INTRODUCCIÓN}

La Laringotraqueitis Infecciosa Aviar (LT) es una enfermedad respiratoria aguda, altamente contagiosa, afecta a pollos de todas las edades y su presencia se ha reportado en la mayoría de países del orbe, siendo común en áreas de intensa producción avícola (Jones, 2004). Basado en informes de resultados serológicos negativos emitidos por diversos laboratorios de diagnóstico privados y el de la UNMSM, supervisados por el SENASA, el OIE le ha otorgado al Perú el estatus sanitario de país libre de la enfermedad.

La importancia de esta enfermedad radica en el impacto económico negativo que origina en los productores y en la economía nacional, ya que, además de los gastos por implementación de procedimientos de despoblación, ocasiona disminución de la producción en reproductoras y gallinas de postura, alta mortalidad y morbilidad, retardo del crecimiento en pollos de carne y complicaciones con infecciones secundarias (Humberd et al., 2002). Además, es un obstáculo para la exportación de productos y subproductos avícolas, pues para realizar esta actividad, también es requisito la ausencia de la enfermedad en el país exportador.

El virus tiene la característica de hacer latencia, principalmente en los ganglios trigéminos, pudiendo reactivarse por factores de estrés, como movimiento o reubicación de las aves y el inicio de la reproducción o postura (Hughes y Jones, 1988; Hughes et $a l ., 1991)$ e inducir a una infección cruzada en aves susceptibles. Se transmite mayormente por vía aerógena, y por contacto con secreciones nasales y oculares que contaminan el agua, alimento y equipos. La transmisión a través del huevo no ha sido demostrada (Guy y Baugust, 2003; Zapata, 2003).

La demostración de anticuerpos contra el virus se realiza principalmente mediante la prueba de ELISA, que posee una alta sensi- bilidad y, además, es una herramienta muy útil para determinar el grado de exposición al VLT; sin embargo, esta prueba no diferencia anticuerpos producidos por virus de campo de aquellos producidos por virus vacunal. Esta característica no es de importancia en el Perú toda vez que no se realiza la vacunación por ser un país libre de la enfermedad (Icochea E, Lima, 2005; Comunicación personal).

Con el fin de obtener información que sirva de sustento técnico en la demostración de que el Perú se mantiene libre de LT, se evaluó la presencia de anticuerpos contra Laringotraqueitis Infecciosa Aviar en gallinas reproductoras de carne y postura, en etapa de producción, mediante la prueba de ELISA, dentro de un contexto de vigilancia.

\section{Materiales y Métodos}

Se utilizó la fórmula de tamaño de muestra para prevalencia límite para determinar el número necesario de aves a utilizar en el estudio. Se eligió una prevalencia referencial de $2 \%$ debido a que no existen estudios previos. De acuerdo a esto, se determinó que el número de aves a analizar fuera de 300 ; sin embargo, se utilizó 360 muestras de sangre provenientes de 18 lotes de gallinas reproductoras de carne y postura, en etapa de producción. Las aves tenían entre 39 y 65 semanas de edad. Las muestras fueron colectadas durante el periodo de julio de 2004 a septiembre de 2005. La identificación y detalles de los lotes examinados se muestran en el Cuadro 1.

Se utilizó un kit comercial de ELISA indirecto para la detección de anticuerpos contra el virus de LT siguiendo las recomendaciones indicadas por el fabricante (Laboratorios Synbiotics). Se usó una dilución de 1:50. Las densidades ópticas fueron medidas a 405 $\mathrm{nm}$ por un lector de ELISA modelo Bio-Tek LX800. Los títulos finales se obtuvieron mediante cálculos obtenidos automáticamente 
Cuadro 1. Resultados de la prueba de ELISA para detectar anticuerpos contra el virus de la Laringotraqueitis Infecciosa Aviar en gallinas reproductoras de carne y postura en la costa central y norte del Perú. Julio 2004 - setiembre 2005

\begin{tabular}{|c|c|c|c|c|c|}
\hline \multirow{2}{*}{$\mathrm{N}^{\mathrm{o}}$ de lote } & \multirow{2}{*}{ Ubicación } & \multirow{2}{*}{$\begin{array}{c}\text { Edad } \\
\text { (Semanas) }\end{array}$} & \multirow{2}{*}{$\begin{array}{l}\text { Tipo de } \\
\text { reproductora }\end{array}$} & \multicolumn{2}{|c|}{ Prueba de ELISA } \\
\hline & & & & Positivo & Negativo \\
\hline 1 & Huacho & 62 & Carne & 0 & 20 \\
\hline 2 & Huacho & 54 & Carne & 0 & 20 \\
\hline 3 & Huacho & 52 & Postura & 0 & 20 \\
\hline 4 & Huacho & 48 & Postura & 0 & 20 \\
\hline 5 & $\begin{array}{l}\text { Santa } \\
\text { Rosa }\end{array}$ & 55 & Carne & 2 & 18 \\
\hline 6 & $\begin{array}{l}\text { Santa } \\
\text { Rosa }\end{array}$ & 53 & Carne & 0 & 20 \\
\hline 7 & Trujillo & 57 & Carne & 0 & 20 \\
\hline 8 & Huacho & 54 & Carne & 0 & 20 \\
\hline 9 & Canta & 65 & Carne & 2 & 18 \\
\hline 10 & Ancash & 56 & Carne & 0 & 20 \\
\hline 11 & Sayan & 52 & Carne & 1 & 19 \\
\hline 12 & Mala & 69 & Postura & 0 & 20 \\
\hline 13 & Mala & 52 & Postura & 1 & 19 \\
\hline 14 & Sayan & 50 & Postura & 0 & 20 \\
\hline 15 & Mala & 50 & Postura & 0 & 20 \\
\hline 16 & Mala & 40 & Postura & 0 & 20 \\
\hline 17 & Ancash & 39 & Carne & 1 & 19 \\
\hline \multirow[t]{2}{*}{18} & Ancash & 62 & Carne & 1 & 19 \\
\hline & & & Total & 8 & 352 \\
\hline
\end{tabular}

por el programa Profile. Las muestras con un $\mathrm{M} / \mathrm{P}$ superiores a 0.150 fueron consideradas positivas y aquellas con $\mathrm{M} / \mathrm{P}$ inferiores o iguales a 0.150 fueron consideradas negativas.

\section{Resultados y Discusión}

El Perú, a partir del año 1996, fue considerado oficialmente libre de Laringotraqueitis
Aviar sin vacunación por la Oficina Interna cional de Epizootias (OIE). Así mismo, no se vacuna contra esta enfermedad en ningún tipo de ave en el país desde hace 30 años, lo cual constituye una ventaja para la industria avícola. Uno de los inconvenientes de la aplicación de vacunas vivas es que origina aves portadoras latentemente infectadas, donde el virus vacunal se puede tornar virulento bajo condiciones de estrés (Guy y Baugust, 2003). 
Las muestras de 12 lotes dieron resultados negativos a la prueba, mientras que 8 muestras de seis lotes tuvieron valores positivos. Por otro lado, es importante señalar que durante el periodo de estudio, no se observaron manifestaciones clínicas respiratorias en ninguno de los lotes de aves reproductoras examinadas.

Las ocho muestras positivas a la prueba de ELISA tuvieron valores de densidad óptica superiores a los controles negativos pero inferiores a los controles positivos. Este tipo de resultados coincide con reacciones falso positivas, las que generalmente dan reacciones de baja intensidad y en bajo porcentaje. Por otro lado, la naturaleza del VLT de ser altamente contagioso no guarda relación con el bajo porcentaje de aves seroreactoras. Además, se debe tener en cuenta que estas reproductoras reciben un intenso programa de vacunación que incluye múltiples vacunas vivas y oleosas. Se ha reportado que la aplicación de vacunas inactivadas induce la producción de aglutininas inespecíficas, las cuales pueden dar lugar a reacciones falso positivas en las pruebas serológicas que se realizan contra diversos agentes (Butcher, 2002).

Las pruebas serológicas de ELISA son convenientes para el monitoreo de enfermedades infecciosas y no infecciosas, pero no son definitivas; en todo caso, un diagnóstico definitivo requiere de pruebas confirmatorias como aislamiento e identificación viral por PCR. Es recomendable que la vigilancia para este agente deba comprender monitoreos periódicos trimestrales con el fin de asegurar que este bajo porcentaje de positividad de los lotes no tenga una tendencia creciente.

\section{Conclusiones}

Ocho aves $(2.2 \%)$, pertenecientes a 6 de 18 lotes de reproductoras de carne y postura presentaron anticuerpos contra el virus de Laringotraqueitis Infecciosa Aviar a través de la prueba de ELISA, aunque en niveles inferiores a los controles positivos, por lo que se concluye que no se pudo demostrar evidencia serológica de exposición al virus.

\section{Literatura Citada}

1. Butcher G. 2002. Factors to consider in serologic testing for Mycoplasma gallisepticum (MG) and Mycoplasma synoviae. Veterinary Medicine-Large Animal Clinical Sciences Department, Florida. [Internet]. Disponible en: http:// edis.ifas.ufl.edu

2. Guy JS, Baugust TJ. 2003. Laryngotracheitis. In: Saif YM, Barnes HJ, Glisson JR, Fadly AM, Mc Dougald LR, Swayne DE (eds). Diseases of poultry. $11^{\text {th }}$ ed. Iowa, USA: Iowa State University Press. 121-133 p.

3. Hughes CS, Jones RC. 1988. Comparison of cultural methods for primary isolation of infectious laryngotracheitis virus from field material. Avian Pathol 17: 295-303.

4. Hughes CS, Williams RA, Gaskell RM, Jordan GT, Bradbury JM, Benett M, Jones RC. 1991. Latency and reactivation of infectious laryngotracheitis vaccine virus. Arch Virol 121: 213-218.

5. Humberd J, Garcia M, Riblet SM, Resurrección RS, Brown TP. 2002. Detection of infectious laryngotracheitis virus in formalin-fixed, paraffinembedded tissues by nested polymerase chain reaction. Avian Dis 46: 64-74.

6. Jones RC. 2004. Respiratory viral diseases-lessons to be learned?. Internat Poultry Prod 12: 11-15.

7. Zapata NR. 2003. Enfermedades más comunes en las aves. Facultad de Medicina Veterinaria y Zootecnia. Universidad Autónoma de Tamaulipas. México. [Internet]. Disponible en: http:// fmvz.uat.edu.mx/aves/\#lar 